\title{
Thyroid hormone-regulated cardiac microRNAs are predicted to suppress pathological hypertrophic signaling
}

\section{Rob Janssen, Marian J. Zuidwijk, Diederik W. D. Kuster, Alice Muller and Warner S. Simonides*}

Department of Physiology, VU University Medical Center, Institute for Cardiovascular Research, Amsterdam, Netherlands

\section{Edited by:}

Domenico Salvatore, Università degli

Studi di Napoli Federico II, Italy

\section{Reviewed by:}

Maria Moreno, University of Sannio, Italy

Tania M. Ortiga-Carvalho,

Universidade Federal do Rio de Janeiro, Brazil

\section{*Correspondence:}

Warner S. Simonides, Department of Physiology, VU University Medical Center, Institute for Cardiovascular Research, v.d. Boechorststraat 7, 1081 BT, Amsterdam, Netherlands e-mail:ws.simonides@vumc.nl
Cardiomyocyte size in the healthy heart is in part determined by the level of circulating thyroid hormone $(\mathrm{TH})$. Higher levels of TH induce ventricular hypertrophy, primarily in response to an increase in hemodynamic load. Normal cardiac function is maintained in this form of hypertrophy, whereas progressive contractile dysfunction is a hallmark of pathological hypertrophy. MicroRNAs (miRNAs) are important modulators of signal-transduction pathways driving adverse remodeling. Because little is known about the involvement of miRNAs in cardiac TH action and hypertrophy, we examined the miRNA expression profile of the hypertrophied left ventricle (LV) using a mouse model of TH-induced cardiac hypertrophy. C57BI/6J mice were rendered hypothyroid by treatment with propylthiouracil and were subsequently treated for 3 days with TH (T3) or saline. T3 treatment increased LV weight by $38 \%(p<0.05)$. RNA was isolated from the LV and expression of 641 mouse miRNAs was determined using Taqman Megaplex arrays. Data were analyzed using RQ-manager and DataAssist. A total of 52 T3-regulated miRNAs showing a $>2$-fold change $(p<0.05)$ were included in Ingenuity Pathway Analysis to predict target mRNAs involved in cardiac hypertrophy. The analysis was further restricted to proteins that have been validated as key factors in hypertrophic signal transduction in mouse models of ventricular remodeling. A total of 27 mRNAs were identified as bona fide targets. The predicted regulation of $19 \%$ of these targets indicates enhancement of physiological hypertrophy, while $56 \%$ indicates suppression of pathological remodeling. Our data suggest that cardiac $\mathrm{TH}$ action includes a novel level of regulation in which a unique set of TH-dependent miRNAs primarily suppresses pathological hypertrophic signaling. This may be relevant for our understanding of the progression of adverse remodeling, since cardiac TH levels are known to decrease substantially in various forms of pathological hypertrophy.

Keywords: thyroid hormone, hyperthyroidism, microRNA, pathway analysis, physiological hypertrophy, pathological hypertrophy

\section{INTRODUCTION}

An increase in the hemodynamic load placed on the heart induces cardiomyocyte hypertrophy. The resulting increase in ventricular mass is aimed at normalizing wall stress and maintaining cardiac output. In the context of chronic pressure and/or volume overload, such as in hypertension, aortic stenosis, valvular disease, or following myocardial infarction, the initially adaptive response is associated with progressive contractile dysfunction and heart failure (1). This pathological remodeling is characterized by distinct changes in cardiac gene expression, increased cardiomyocyte apoptosis, and fibrosis. Typical phenotypic changes include a shift in expression from the fast contractile protein myosin heavy chain $\alpha$ (Myh6) to the slow $\beta$ isoform (Myh7) (2), reduced expression of sarcoplasmic reticulum $\mathrm{Ca}^{2+}$-ATPase (Serca2a) (2, 3 ), and increased expression of fetal genes [e.g., $\alpha$-skeletal actin, atrial natriuretic peptide (Anp), B-type natriuretic peptide (Bnp), deiodinase type III (Dio3) (4-6)].

In contrast, cardiac hypertrophy in response to increased levels of circulating thyroid hormone (TH) (hyperthyroidism) is not associated with adverse remodeling or impairment of contractility in both animals and human beings (7-9), in spite of the chronically increased hemodynamic load, which also in this case is the principal trigger of cardiomyocyte growth $(10,11)$. TH-induced remodeling is, therefore, considered physiological and is similar to physiological ventricular hypertrophy induced by pregnancy or chronic exercise training, and is equally reversible (12-14).

The distinction between stimuli and the related signaltransduction pathways that cause either pathological or physiological hypertrophy has not been without discussion. It has been presumed that the duration of the stimulus, i.e., chronic or intermittent, is the key difference determining the two forms of hypertrophy. Nevertheless, studies using intermittent pressure overload showed that although the resulting hypertrophy appeared to be adaptive, the cellular characteristics already showed all features of pathological remodeling (15). This suggests that certain aspects of the different stimuli and down-stream processes determine the phenotype of hypertrophy, rather than the duration of the exposure to the stimuli (16).

Gain- and loss-of-function studies have delineated numerous signal-transduction pathways which relay the various neurohumoral and mechanical signals that drive cardiac hypertrophy [see Ref. (16) for an extensive review]. There is considerable overlap 
and cross-talk between these pathways and although some pathways appear to mediate physiological, and others, pathological hypertrophy, the mechanisms underlying development of either one of these distinct phenotypes in response to chronic overload are not clear (16). In the case of $\mathrm{TH}$, some effects of pathological signaling will be countered by direct transcriptional regulation of genes such as Myh6, Myh7, and Serca2a $(7,17)$, mediated by the TH receptors $\alpha 1$ or $\beta 1$ (18). Both receptors are capable of mediating the transcriptional T3 effect, and they are also implicated in the non-genomic T3 effect involving stimulation of the phosphoinositide 3-kinase [PI3K (p110 $\alpha$ )]-Akt pathway (19-21). However, additional mechanisms are expected to account for the full suppression of adverse remodeling.

Recent studies have shown an important role for microRNAs (miRNAs) in the regulation of cardiac gene expression by virtue of their ability to induce degradation of specific target mRNAs or reduce the efficiency of translation $(22,23)$. Although miRNAs are generally considered to fine-tune gene expression, critical roles of individual miRNAs have been established in various aspects of pathological cardiac hypertrophy (22-25). For example, miR208a is required for overload-induced pathological remodeling, including cardiomyocyte hypertrophy, $M y h$ isoform switching, and fibrosis $(26,27)$. Furthermore, forced expression of miR208a induces pathological remodeling (27), whereas blocking of miR-208a attenuates hypertension-induced cardiac dysfunction (28).This miRNA is encoded in an intron of the Myh6 gene, which is transcriptionally stimulated by TH. Consequently, and perhaps counter intuitively, expression of this "pathological" miRNA is increased in hyperthyroidism $(27,29)$. Little else is known about the TH-dependency of miRNA expression in the heart, despite the obvious potential of miRNA-mediated effects. However, studies in liver and skeletal muscle $(30,31)$ have identified a number of TH-responsive miRNAs, which are also known to play a role in remodeling adult cardiomyocytes and differentiating cardiomyocyte progenitor cells (32-35).

As a first step in elucidating a role of miRNAs in cardiac $\mathrm{TH}$ action, we set out to identify $\mathrm{TH}$-responsive cardiac miRNAs using a mouse model of physiological hypertrophy induced by TH. To increase the sensitivity and to limit long-term secondary effects, TH-deficient mice were treated for 3 days with $\mathrm{T} 3$, the active form of TH. Target analysis of the 52 differentially regulated miRNAs indicated limited potentiation of pathways involved in physiological hypertrophy, but a marked suppression of pathways associated with pathological hypertrophy. Our data suggest that cardiac TH action includes a novel level of regulation in which a unique set of TH-dependent miRNAs suppresses pathological hypertrophic signaling.

\section{MATERIALS AND METHODS \\ ANIMALS}

Two groups of six male C57BL/6 mice (10-12 weeks, Charles Rivers) were used. Both groups were allowed ad libitum access to food containing PTU (Teklad $+0.15 \%$ propylthiouracil) for 44 days to induce hypothyroidism. Six mice were injected (IP) with a supra-physiological dose of $5 \mu \mathrm{g}$ T3 in $20 \mu \mathrm{l}$ saline at day 42, 43, and 44 (corresponding to $0.21-0.24 \mu \mathrm{g}$ T3/g BW); the remaining six hypothyroid mice were injected with $20 \mu \mathrm{l}$ saline. Animals were sacrificed at day 45 . The heart was excised and left and right ventricle (LV, RV) and septum were dissected, weighed, immediately frozen in liquid nitrogen, and stored at $-80^{\circ} \mathrm{C}$. Tibia length was determined for normalization purposes. Plasma T3 levels were determined by AccuBind ELISA kits (Monobind Inc., Lake Forest, CA) according to the manufacturer's instructions. Animals were housed individually and all experiments complied with the Guide for Care and Use of Laboratory Animals of the National Institutes of Health (NIH Publication no. 86-23, revised 1996) and were approved by the Institutional Animal Care and use Committees of VU University Medical Center Amsterdam.

\section{RNA ISOLATION}

Total RNA was isolated from approximately $20 \mathrm{mg}$ LV using the mirVana Paris isolation kit (Ambion, Foster City, CA). To improve cell lysis, frozen samples were sliced into $10 \mu \mathrm{m}$ sections using a cryostat. The tissue sections were dissolved in $2 \mathrm{ml}$ cell disruption buffer. Three aliquots of $500 \mu \mathrm{l}$ lysate were transferred to Eppendorf tubes and $500 \mu l$ of $2 \times$ denaturation solution, containing guanidinium thiocyanate, was added to each tube to prevent RNA degradation by cellular ribonucleases. Subsequently, an equal volume of acid-phenol:chloroform was added to separate RNA from DNA and protein (36). The aqueous phase was transferred to a fresh tube. To make sure there was no DNA or protein left, we repeated the previous step. Next, 1.25 volumes of $100 \%$ ethanol was added before each extract was transferred onto an individual filter cartridge, centrifuged, and washed. The bound RNA fraction was pretreated with DNAseI (Qiagen, Venlo, the Netherlands) before $105 \mu$ l elution buffer was added to each filter cartridge to collect the total RNA fraction. It should be noted that the capacity of the filter is limited, requiring the use of three cartridges per sample. RNA concentration and quality were measured either with the Nanodrop1000 (Thermo Scientific, Wilmington, DE) or the 2100 Bioanalyzer (Agilent Technologies, Santa Clara, CA). Samples were stored at $-80^{\circ} \mathrm{C}$, at which temperature miRNAs are stable (37).

\section{QUANTITATIVE REAL-TIME PCR}

To analyze mRNA levels of the TH-regulated myosin heavy chains (Myh6, Myh7), $10 \mu \mathrm{l}$ DNaseI-treated total RNA was transcribed to cDNA using Cloned AMV first strand cDNA synthesis (Invitrogen, Carlsbad, CA, USA). RNA concentration was adjusted to $12.5 \mathrm{ng} / \mu \mathrm{l}$. Quantitative real-time polymerase chain reaction (qPCR) was performed using MESA GREEN qPCR MasterMix Plus for SYBR assay (Eurogentec, Seraing, Belgium) and specific primers (38) for Myh6 (sense: 5'-GACCAGGCCAATGAGTACCG-3, antisense: $5^{\prime}$-GCCTAGCCAACTCCCCGTTC-3') and $M y h 7$ (sense: $5^{\prime}$ CGCTCCACGCACCCTCACTT-3' ${ }^{\prime}$, antisense: $5^{\prime}$-GTCCATCACC CCT GGAGAC-3') in an Applied Biosystems model 7700 (Applied Biosystems, Foster City, CA). Expression levels of Hprt (sense: 5'-TCCCTGGTTAAGCAGTACAGCC-3', antisense: $5^{\prime}$-CGAGAGGTCCTTTTCACCAGC-3') were used for normalization. For comparison of the relative gene expression $\left[2^{\text {(Ct HPRT }-C t \text { target })}\right]$ of the two groups, a two-tailed Student $t$-test was performed to calculate $p$ values. 
Table 1 | Effects of short-term T3 treatment on BW, HW, and plasma T3 levels.

\begin{tabular}{lcc}
\hline & HO & HOT3 \\
\hline Anatomic data & & \\
$\quad$ Body weight day 0 $(\mathrm{g})$ & $22.1 \pm 0.5$ & $22.1 \pm 0.6$ \\
$\quad$ Body weight day $44(\mathrm{~g})$ & $22.7 \pm 0.4$ & $22.6 \pm 0.5$ \\
$\quad$ Total heart weight/TL $(\mathrm{mg} / \mathrm{cm})$ & $41.3 \pm 1.1$ & $58.1 \pm 0.6^{*}$ \\
LV weight/TL $(\mathrm{mg} / \mathrm{cm})$ & $24.0 \pm 1.4$ & $33.1 \pm 1.2^{*}$ \\
Thyroid hormone status & & \\
T3 levels $(\mathrm{nM})$ & $0.1 \pm 0.1$ & $47.5 \pm 4.2^{*}$ \\
\hline
\end{tabular}

Twelve mice were allowed ad libitum access to food containing PTU for 44 days. Six randomly chosen mice were injected with $T 3$ at day 42, 43, and 44. Controls received vehicle. Mice were sacrificed at day 45. Body weight remained unchanged during the experiment. Total heart weight increased by $41 \%$, and $L V$ weight increased by $38 \%$. T3 treatment resulted in 475 times higher T3 levels in the hyperthyroid mice. Heart weight was corrected for TL, tibia length; HO, hypothyroid; HOT3, hyperthyroid. Values are means $\pm S E M$; ${ }^{*} p<0.05$.

\section{MicroRNA EXPRESSION ANALYSIS}

TaqMan miRNA Megaplex array (Applied Biosystems, Foster City, CA) was used to analyze miRNAs expression profiles. To synthesize cDNA, $3 \mu \mathrm{l}$ RNA was added to $4.5 \mu \mathrm{l}$ of RT-PCR reaction mix consisting of specially designed Megaplex RT primers (Rodent pool A or B, v3), dNTPs, MultiScribe reverse transcriptase, $10 \times$ reaction buffer, $\mathrm{MgCl}_{2}$, and RNase inhibitor. Subsequently, the mixture was subjected to 40 cycles for $2 \mathrm{~min}$ at $16^{\circ} \mathrm{C}$, for $1 \mathrm{~min}$ at $42^{\circ} \mathrm{C}$, and for $1 \mathrm{~s}$ at $50^{\circ} \mathrm{C}$, followed by $5 \mathrm{~min}$ at $85^{\circ} \mathrm{C}$ and cooling to $4^{\circ} \mathrm{C}$. A pre-amplification was performed to increase the cDNA quantity, thereby improving the sensitivity of miRNA detection (39). The pre-amplification mixture consisted of $2.5 \mu \mathrm{l}$ RT product, $12.5 \mu \mathrm{l}$ TaqMan PreAmp master mix, and Megaplex PreAmp primers. The mixture was incubated for $10 \mathrm{~min}$ at $95^{\circ} \mathrm{C}, 2 \mathrm{~min}$ at $55^{\circ} \mathrm{C}, 2 \mathrm{~min}$ at $72^{\circ} \mathrm{C}$ followed by 12 cycles of $15 \mathrm{~s} 95^{\circ} \mathrm{C}$ and $4 \mathrm{~min}$ at $60^{\circ} \mathrm{C}$, inactivated for $10 \mathrm{~min}$ at $99.9^{\circ} \mathrm{C}$, and cooled down to $4^{\circ} \mathrm{C}$. Each product was diluted by adding $75 \mu \mathrm{l} 0.1 \times \mathrm{TE}(\mathrm{pH} 8.0)$. After $9 \mu \mathrm{l}$ diluted pre-amplified target cDNA was added to $450 \mu \mathrm{l} 2 \times$ TaqMan Universal master mix (w/o amperase) and $441 \mu \mathrm{l}$ nuclease free water, $100 \mu \mathrm{l}$ mixture
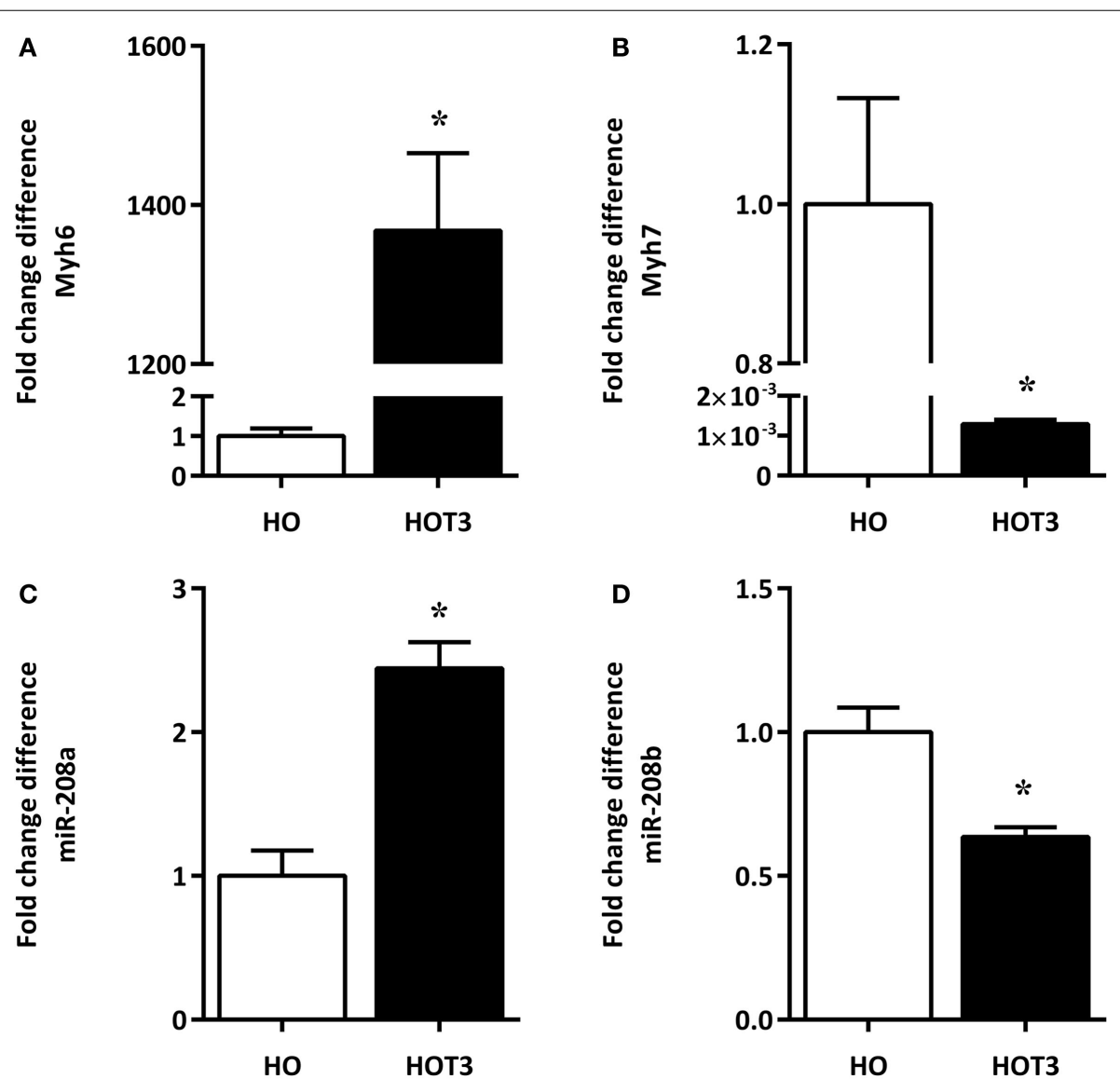

FIGURE 1 |The effects of T3 treatment on Myh-isoform expression and corresponding miRNAs. RNA was isolated from the LV of six hypothyroid (HO) and six hyperthyroid (HOT3) mice. The low Myh6 [(A), open bar] and high Myh7 mRNA levels [(B), open bar] are indicative of the low cardiac T3 state in the hypothyroid animals. The TH-responsiveness of both genes was

evident from the shift in expression of Myh6 [(A), solid bar] and Myh7 [(B), solid bar] as a result of T3 treatment. MiRNAs 208a and 208b are located within Myh6 and Myh7. The expression pattern of miR-208a (C) and miR-208b (D) in these conditions is similar to the pattern of their host genes. $\mathrm{HO}$ set to 1 , values are means $\pm \mathrm{SEM}$; ${ }^{*} p<0.05$. 


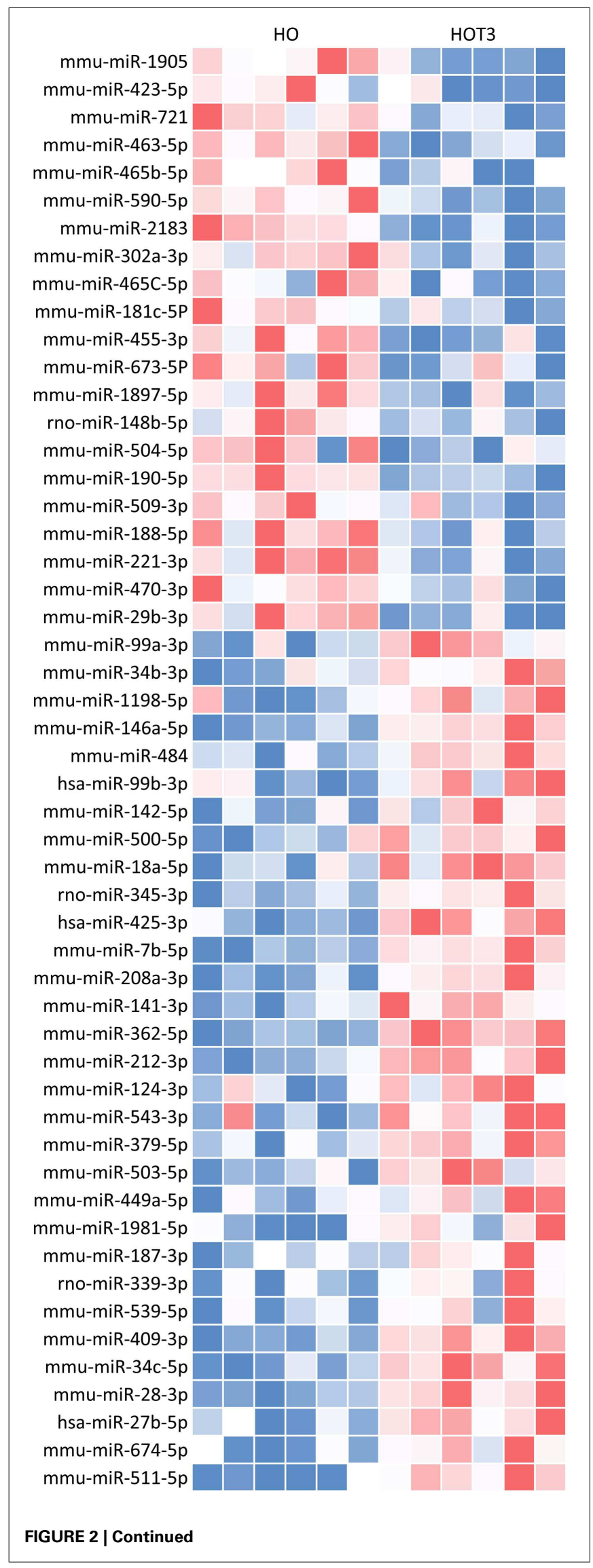

\section{FIGURE 2 | Continued}

T3 treatment for $\mathbf{3}$ days revealed a unique miRNA profile in the

hypertrophied LV. Expression data of 641 known mouse miRNAs were obtained with TaqMan Megaplex arrays (v3. A and B, rodent) and analyzed using RQ-manager (v1.2) and DataAssist (v3.0). The depicted heat map represents a unique profile of 52 differentially expressed miRNAs after 3 days of $\mathrm{T} 3$ treatment with a $\mathrm{FC}> \pm 2$ and a $p$-value $<0.05$. Blue, low; red, high.

per lane was added to the TaqMan array card. The qPCR was performed on a 7900HT system with TLDA arrays. MammU6 and snoRNA202 were the most stable miRNAs and, therefore, chosen as endogenous controls. Comparative threshold $(\mathrm{Ct})$ values were analyzed by SDS software v2.3 before being exported to RQ-manager v1.2 (Applied Biosystems). Data were next exported to DataAssist v3.0 (Applied Biosystems) for statistical analyses. MiRNAs with Ct's above 38 were designated "not-expressed" and excluded from the analyses. Data were only considered when expression of a particular miRNA was observed in at least five mice of each group. A two-tailed Student $t$-test was used for two-group comparisons.

\section{PREDICTION OF MIRNA TARGETS}

To obtain an overview of the predicted miRNA targets and their role in biological processes, we analyzed significantly differentially regulated miRNAs with Ingenuity Systems Pathway Analysis software (IPA, Ingenuity Systems, www.ingenuity.com). Briefly, after analyzing the expression of all the detected miRNAs using DataAssist, a list of significantly differentially regulated miRNAs was uploaded to IPA. The uploaded miRNAs were analyzed using the microRNA Target Filter to find experimentally validated miRNA targets from Tarbase and miRecords, as well as highly predicted miRNA-mRNA pairing from Targetscan. Additionally, IPA includes peer-reviewed biological literature describing miRNAtarget interactions. We focused only on miRNAs that were up- or downregulated by at least a fold change (FC) of $> \pm 2$ and $p$-value of $<0.05$. Targets expressed in heart tissue were used for further in silico analysis.

\section{RESULTS}

\section{LEFT VENTRICULAR HYPERTROPHY INDUCED BY T3 TREATMENT}

Hypothyroidism was induced using the established 40-day protocol of ad libitum access to food containing PTU (40). Indicative of the low plasma T3 levels and in agreement with earlier studies, growth was arrested in these animals (Table 1) (40). T3 treatment for three consecutive days resulted in a $\sim 475$-fold increase of plasma T3. Cardiac hypertrophy was evident from a $41 \%$ increase in total heart weight, and a $38 \%$ increase in weight of the LV free wall, which was used in all further analyses (Table 1).

A total RNA fraction was isolated from approximately $20 \mathrm{mg}$ LV tissue. Expression analysis of the TH-regulated Myh6 and $M y h 7$ genes indicated the low cardiac T3 state in the hypothyroid animals, showing low Myh6 and high Myh7 mRNA levels (2). The TH-responsiveness of both genes was evident from the shift in expression of Myh6 and Myh7 as a result of T3 treatment (Figures 1A,B). 


\section{ALTERED miRNA EXPRESSION PROFILE INDUCED BY T3 TREATMENT}

Using a platform based on stem-loop primers, we observed 45 significantly upregulated and 104 significantly downregulated miRNAs as a result of T3 treatment (Table S1 in Supplementary Material). Among these miRNAs, 208a and 208b are examples of miRNAs known to be up- and downregulated, respectively, in response to increasing TH levels $(27,29)$. Both miR-208a and 208b followed the expression of their corresponding host genes Myh6 and $M y h 7$, respectively (Figures $\mathbf{1 C}, \mathbf{D}$ ).

\section{ANALYSIS OF POTENTIAL TARGET mRNAs OF T3-REGULATED miRNAs}

Of the total of 149 differentially regulated miRNAs, 52 met the criteria of at least a twofold increase or a $50 \%$ decrease and having a $p$-value $<0.05$. This group of 52 forms a unique signature of miRNAs differentially regulated after 3 days of T3 treatment (Figure 2). To test for potential target mRNAs, in silico target prediction was performed using a web-based entry tool, IPA. Thirty-one out of the 52 miRNAs had targeting information available in the Ingenuity database and could be used in the IPA analysis (Table S2 in Supplementary Material). The predicted interaction between miRNA and its target mRNA was based on sequence homology of the miRNA seed region and the target sequence present in the $3^{\prime}$ UTR of the mRNA. The analysis was furthermore restricted to mRNAs known to be expressed in heart tissue. In this way, a total of 3274 mRNAs were identified as potential targets of the group of
31 miRNAs. An IPA “core" analysis was subsequently performed to relate the predicted target mRNAs to known biological functions and processes. This revealed that the predicted target mRNAs were significantly represented in "cardiovascular system development and function," "cell death and survival," "cellular growth and proliferation," "energy metabolism," and "lipid metabolism" (Figure 3).

\section{PATHWAY ANALYSIS OF POTENTIAL TARGET mRNAs INVOLVED IN T3-INDUCED CARDIAC HYPERTROPHY}

We next focused our analyses on target mRNAs encoding proteins which have been shown to be critical components of hypertrophic signaling pathways, i.e., the IGF-1-, NFAT-, $\mathrm{Ca}^{2+}$-, GPCR-, JAK/STAT-, PI3K/Akt-, ERK/MAPK-, and TH-signaling pathways (16) and which have been validated in mouse models of pathological and/or physiological hypertrophy. Analysis was furthermore limited to mRNAs that are solely targeted by either up- or downregulated miRNAs, so that the effect of miRNA regulation on the expression of these signaling components is unequivocal. This approach resulted in 27 candidates (Figure 4). In depth analyses using IPA and additional literature searches revealed that the predicted regulation of 5 of these targets (19\%) results in enhancement of physiological hypertrophy, whereas regulation of 15 of these targets $(56 \%)$ results in suppression of pathological remodeling (Table 2 ).

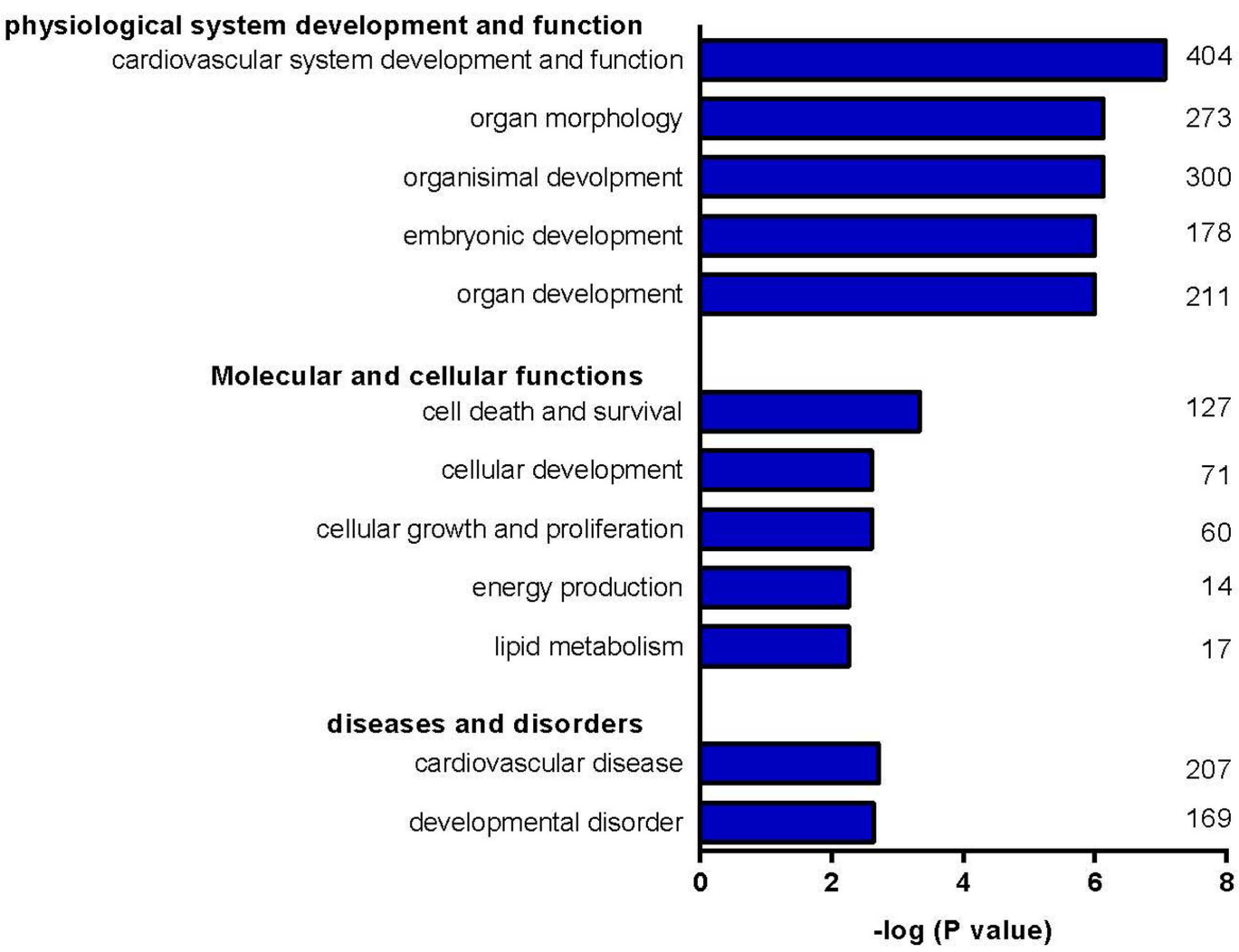

FIGURE 3 | Clustering of target mRNAs into biological groups Clustering of predicted target mRNAs into biological groups was performed with IPA. Predicted target mRNAs were represented in processes involved in "cardiovascular system development and function," "cell death and survival," "cellular growth and proliferation," "energy metabolism," and "lipid metabolism." Numbers indicate the number of target mRNAs involved in the corresponding process. 


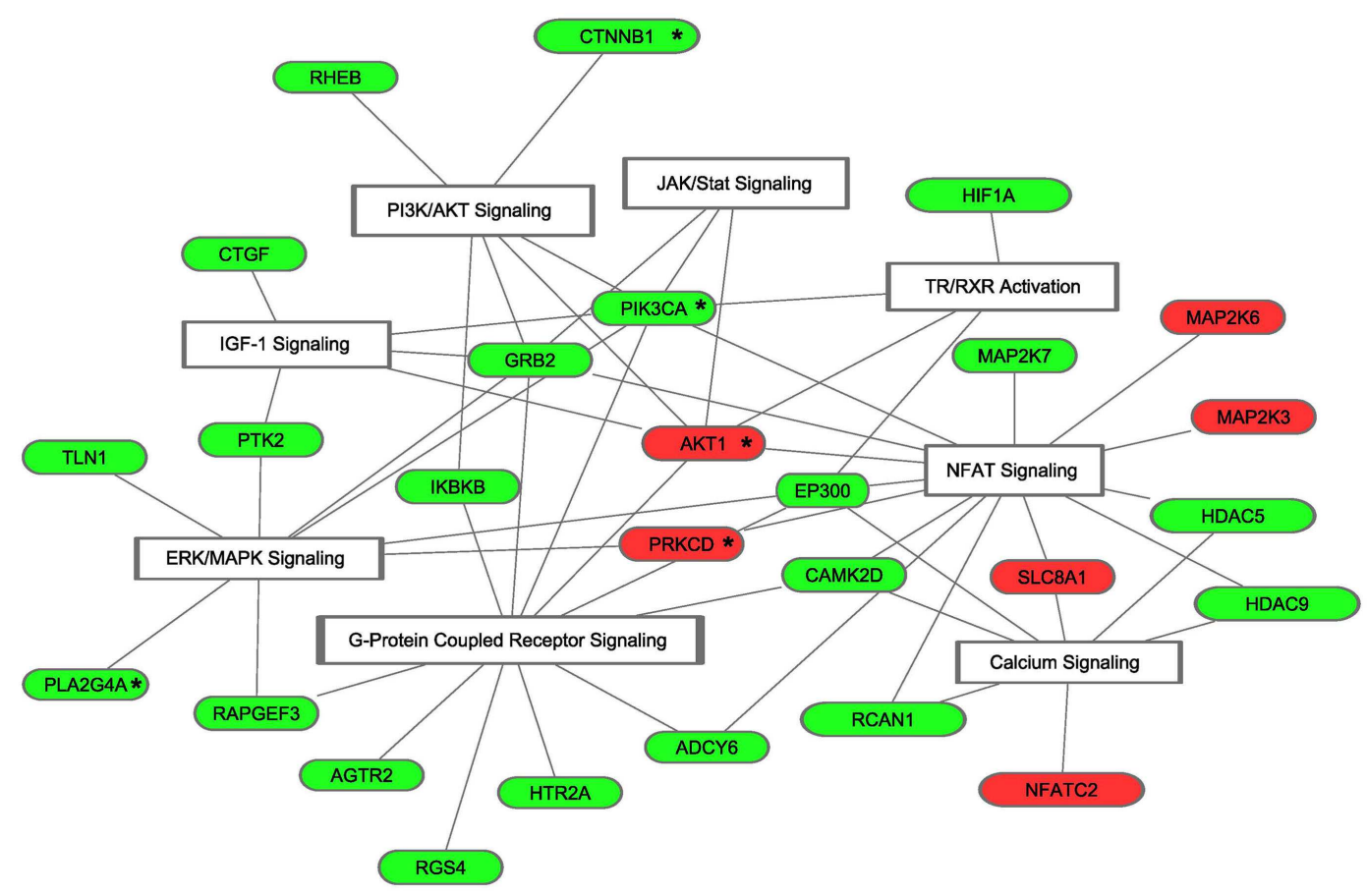

FIGURE 4 | Predicted target mRNAs involved in signature pathways of cardiac hypertrophy. Of the 2312 mRNAs that were targeted by either up- or downregulated miRNAs, 27 bona fide targets were found to be involved in cardiac hypertrophy. The presented molecules are members of at least one of the eight selected signature transduction pathways involved in the development of cardiac hypertrophy. Red, the corresponding miRNA was shown to be downregulated in HOT3, which resulted in a predicted upregulation of its target mRNA; green, the corresponding miRNA was shown to be upregulated in hyperthyroid LV, which resulted in a predicted downregulation of its target mRNA. "** Indicates target mRNAs involved in physiological hypertrophy.

\section{DISCUSSION}

In this paper, we describe an unbiased in silico approach to analyze differentially expressed cardiac miRNAs in the physiologically hypertrophied mouse heart as a result of T3 treatment. Our data show that next to the known extra-cardiac effects of T3 on the heart due to an increase in hemodynamic load $(10,11)$, and modulation of TH-regulated genes (2,3), a T3-dependent miRNA profile is expressed which is predicted to primarily suppress pathways involved in pathological hypertrophy, with some enhancement of pathways involved in physiological hypertrophy.

We chose to use hypothyroid mice treated for only 3 days with T3 to optimize the identification of T3-responsive miRNAs. The reciprocal regulation of the $\mathrm{TH}$-regulated myosin genes, Myh6 and $M y h 7$, and the $41 \%$ increase in heart weight are in line with previous findings $(14,66,67)$. Earlier studies established that the T3-induced increase in heart weight is caused by an increase in cell size and is not accompanied by fibrotic deposition $(68,69)$. Some of the observed changes in the miRNA expression profile of the hypertrophied LV, following T3 treatment, also confirmed earlier results. The observed reciprocal expression of the miRNAs 208a and 208b, which originate from introns of Myh6 and $M y h 7$, respectively, has been reported before $(27,29)$. As already mentioned in the Section "Introduction," expression of miR-208a has been implicated in the development of pathological hypertrophy. Mir-208a targets the Thyroid Hormone Receptor Associated
Protein 1 (Thrap1) $(26,27,70)$, which is a component of the TH-receptor/co-factor complex that mediates transcriptional regulation of T3-dependent genes $(26,27,71,72)$. Increased miR-208a expression is, therefore, expected to decrease T3 action, because Thrap1 expression will be decreased. However, our data suggest that in the presence of high levels of T3, the effect of miR-208a on the efficiency of T3-regulated gene expression and pathological signaling is minimal, since it does not prevent T3-induced gene expression nor does it result in a pathological phenotype under this condition. Also, in line with earlier results, the cardiac miRNAs, miR-206 and miR-1, which were shown to be downregulated by TH in liver and skeletal muscle $(30,31)$, were found to be suppressed by $\mathrm{T} 3$ treatment in the present study.

Furthermore, our results are consistent with data obtained using a model of exercise-induced cardiac hypertrophy (73), showing a significant downregulation of miR-26b, 27a, and 143 after 7 days of exercise. Moreover, a trend toward downregulation of miR-195 and 499 was observed in that study, where we found significant downregulation of both miRNAs after 3 days of T3 treatment. Exercise-induced physiological cardiac growth has been considered similar to TH-induced physiological hypertrophy (16), and our data suggest that this similarity may involve regulation by miRNAs.

In-depth analysis of our set of 149 differentially expressed miRNAs revealed 52 with a $\mathrm{FC}> \pm 2$ and a $p$-value $<0.05$, which 
Table 2 | Predicted interaction of T3-induced miRNA expression and hypertrophic signaling pathways

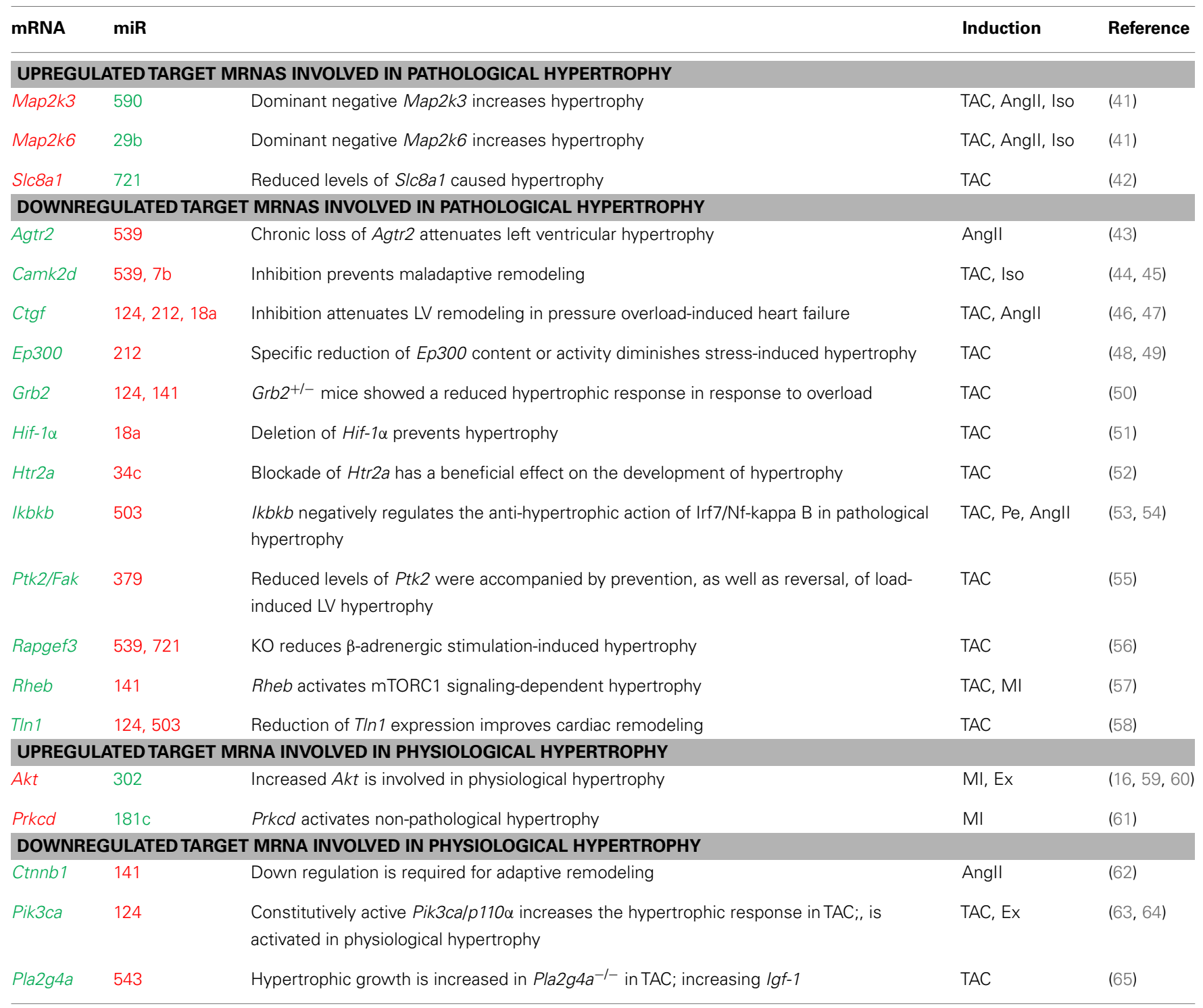

IPA and additional literature were used to evaluate the role of 27 bona fide target mRNAs in the development of cardiac hypertrophy (see Figure 4). Twenty of the initial 27 target mRNAs were shown to be validated in mouse models for cardiac hypertrophy, as indicated in the table, together with the relevant literature and description of the principal findings. These models included transverse (ascending) aortic constriction (TAC), LV remodeling following myocardial infarction (MI), and Angiotensin II (AngIII), isoproterenol (Iso), and phenylephrine (Pe) induced pathological hypertrophy, and exercise (Ex) induced physiological hypertrophy. The identified T3-regulated miRNAs are depicted in green (reduced expression) or red (increased expression). The direction of change of the predicted target mRNAs is similarly color coded. Fifteen target mRNAs are predicted to be regulated by the indicated miRNAs in such a way that pathological signaling is suppressed. For example, Map2k3 has been shown in a TAC model to suppress pathological remodeling. Consequently, its upregulation by decreased miR-590 expression is considered to limit pathological signaling. Likewise, Camk2d is required for TAC-induced pathological remodeling and its suppression by the upregulated miRNAs 539 and $7 \mathrm{~b}$ is again considered to limit pathological signaling. The remaining five target mRNAs are regulated in such a way that physiological signaling is enhanced.

formed a miRNA signature unique for short-term T3 treatment in the LV. To test for potential target mRNAs, in silico target prediction was performed using IPA. Thirty-one of the 52 had targeting information available in the database, resulting in 3274 confirmed or highly predicted targets. Core analysis included in IPA was used to interpret the target mRNA data in the context of biological functions and processes. Besides "cardiovascular system development and function," processes in which target mRNAs are known to be involved included "cell death and survival," "cellular growth and proliferation," "energy metabolism," and "lipid metabolism." These findings are in accordance with the concept that TH plays a determining role in cell proliferation, differentiation, and metabolism $(74,75)$.

Next, the analysis was limited to target mRNAs that were solely targeted by either up- or downregulated miRNAs, so that the effect of miRNA regulation on the expression of these signaling 
components was unequivocal, resulting in 2312 target mRNAs. Subsequently, we searched for target mRNAs involved in cardiac hypertrophy pathways. Signature cardiac hypertrophy pathways, such as IGF-1-, PI3K/Akt-, JAK/STAT-, and TH-signaling pathways, are mostly associated with physiological hypertrophy, whereas GPCR-, $\mathrm{Ca}^{2+}$-, ERK/MAPK-, and NFAT signaling pathways are associated with pathological hypertrophy (16). Analysis revealed 27 target mRNAs that were indicated by IPA to be part of at least one of the signature pathways mentioned above and have been validated in models of pathological and/or physiological hypertrophy. In the setting of T3-induced hypertrophy, the predicted regulation of $19 \%$ of these targets indicates enhancement of physiological hypertrophy, while $56 \%$ indicates suppression of pathological remodeling.

For instance, Hifl $\alpha$ and Camk2d are upregulated in both human and mouse pathological hypertrophy $(51,76)$. Inactivation of Hifl $\alpha$ in TAC mouse models resulted in a beneficial effect preventing cardiac growth $(51,77)$. Transgenic mouse models overexpressing Camk2d, the predominant isoform expressed in the heart, established the involvement of Camk2d in pathological hypertrophy (78). Specific inhibition of Camk2d attenuated cardiac growth in response to several hypertrophic stimuli $(44,45,79)$. It was consequently suggested that target-specific inhibition of Camk2d may be a useful treatment of cardiac hypertrophy (80). Another example is connective tissue growth factor, Ctgf, which in the present study is targeted by three upregulated miRNAs, miR-212, 124, and $18 \mathrm{a}$, suggesting a strong downregulation. It has been reported that while the initial overexpression of Ctgf activates $A k t$, triggering adaptive hypertrophy, the prolonged Ctgf overexpression eventually leads to heart failure $(46,81)$. These, and other target mRNAs listed in Table 2 are predicted by IPA to be downregulated by T3dependent miRNAs, suggesting that fine-tuning by these miRNAs attenuates the development of pathological hypertrophy.

Likewise, it has been described that increased expression of the serine/threonine kinase $A k t$ results in cell growth (82), both in pathological and in physiological hypertrophy (83). Recent studies using Akt knockout mouse models suggest that $A k t$ is more likely to be required for physiological hypertrophy than for pathological hypertrophy (59). It has been shown that short-term activation of $A k t$ is associated with cardiac protection (84), utilization of glucose, instead of free fatty acids, and improvement of cardiac contractility (85). For Ctnnb1/Beta-catenin, a key molecule in pathways associated with cardiac hypertrophy, it has been shown that decreased expression levels are important for the process of adaptive left ventricular remodeling (62), suggesting that the predicted fine-tuning of these target mRNAs enhances physiological hypertrophy.

Although we limited our analyses to miRNAs that were strongly responsive to $\mathrm{T} 3$ treatment, and to target mRNAs that have been validated in mouse models, future studies should be aimed at confirming the predicted regulation of the target mRNAs and their proteins. At present, our data suggest that cardiac T3-action includes a novel level of regulation in which a unique set of T3-dependent miRNAs enhances some aspects of physiological hypertrophy, but primarily suppresses pathological hypertrophic signaling. This suggests a mechanism that may in part explain why cardiac hypertrophy due to high circulating T3 levels does not progress to dysfunction, in spite of the chronic hemodynamic overload, which in the context of cardiovascular disease is the principal trigger of pathological hypertrophy (10). This proposed mechanism may be relevant for our understanding of the progression of adverse remodeling. As in other severe illnesses, heart failure is often associated with reduced plasma T3 levels, the so-called nonthyroidal illness syndrome (86). Clinical studies have shown that the extent of the reduction is an independent predictor of mortality in patients with chronic heart failure $(87,88)$. In addition, we and others have shown that increased cardiac activity of the $\mathrm{TH}$ inactivating enzyme, Dio3, results in a local hypothyroid condition in the pathologically remodeled heart due to pressure overload or following myocardial infarction $(38,89,90)$. Indeed, alterations in gene expression in the failing heart are to some extent similar to the genetic profile of a hypothyroid heart (4). Taken together, this suggests that reduced T3-signaling in the hemodynamically overloaded heart will aggravate adverse remodeling by releasing the T3-dependent miRNA brake on these pathological signaling pathways. Manipulation of these miRNAs may be an additional option in the ongoing development of miRNA-based therapeutics for the treatment of heart failure $(91,92)$.

\section{SUPPLEMENTARY MATERIAL}

The Supplementary Material for this article can be found online at http://www.frontiersin.org/Journal/10.3389/fendo.2014.00171/ abstract

\section{REFERENCES}

1. Sutton MGSJ, Sharpe N. Left ventricular remodeling after myocardial infarction: pathophysiology and therapy. Circulation (2000) 101:2981-8. doi:10.1161/ 01.CIR.101.25.2981

2. Ojamaa K, Kenessey A, Shenoy R, Klein I, Gerdes AM, Iervasi G, et al. Thyroid hormone metabolism and cardiac gene expression after acute myocardia infarction in the rat. Am J Physiol Endocrinol Metab (2000) 279(6):E1319-24.

3. Bers DM, Eisner DA, Valdivia HH. Sarcoplasmic reticulum Ca2+ and heart failure: roles of diastolic leak and Ca2+ transport. Circ Res (2003) 93:487-90. doi:10.1161/01.RES.0000091871.54907.6B

4. Pol CJ, Muller A, Simonides WS. Cardiomyocyte-specific inactivation of thyroid hormone in pathologic ventricular hypertrophy: an adaptative response or part of the problem? Heart Fail Rev (2010) 15:133-42. doi:10.1007/s10741-0089133-7

5. Dirkx E, da Costa Martins P, De Windt LJ. Regulation of fetal gene expression in heart failure. Biochim Biophys Acta (2013) 1832(12):2414-24. doi:10.1016/j. bbadis.2013.07.023

6. Razeghi P, Young ME, Alcorn JL, Moravec CS, Frazier OHH, Taegtmeyer H. Metabolic gene expression in fetal and failing human heart. Circulation (2001) 104:2923-31. doi:10.1161/hc4901.100526

7. Klein I, Ojamaa K. Thyroid hormone and the cardiovascular system. N Engl J Med (2001) 344:501-9. doi:10.1056/NEJM200102153440707

8. Ching GW, Franklyn J, Stallard TJ, Daykin J, Sheppard MC, Gammage MD. Cardiac hypertrophy as a result of long-term thyroxine therapy and thyrotoxicosis. Heart (1996) 75:363-8. doi:10.1136/hrt.75.4.363

9. Rodondi N, Newman AB, Vittinghoff E, de Rekeneire N, Satterfield S, Harris $\mathrm{TB}$, et al. Subclinical hypothyroidism and the risk of heart failure, other cardiovascular events, and death. Arch Intern Med (2005) 165:2460-6. doi:10.1001/ archinte.165.21.2460

10. Danzi S, Klein I. Thyroid hormone and blood pressure regulation. Curr Hypertens Rep (2003) 5:513-20. doi:10.1007/s11906-003-0060-7

11. Trivieri MG, Oudit GY, Sah R, Kerfant B-G, Sun H, Gramolini AO, et al. Cardiacspecific elevations in thyroid hormone enhance contractility and prevent pressure overload-induced cardiac dysfunction. Proc Natl Acad Sci U S A (2006) 103:6043-8. doi:10.1073/pnas.0601072103 
12. Biondi B, Palmieri EA, Fazio S, Cosco C, Nocera M, Saccà L, et al. Endogenous subclinical hyperthyroidism affects quality of life and cardiac morphology and function in young and middle-aged patients. J Clin Endocrinol Metab (2000) 85:4701-5. doi:10.1210/jcem.85.12.7085

13. Klein I, Hong C. Effects of thyroid hormone on cardiac size and myosin content of the heterotopically transplanted rat heart. J Clin Invest (1986) 77:1694-8. doi:10.1172/JCI112488

14. Kuzman JA, O'Connell TD, Gerdes AM. Rapamycin prevents thyroid hormoneinduced cardiac hypertrophy. Endocrinology (2007) 148:3477-84. doi:10.1210/ en.2007-0099

15. Perrino C, Naga Prasad SV, Mao L, Noma T, Yan Z, Kim H-S, et al. Intermittent pressure overload triggers hypertrophy-independent cardiac dysfunction and vascular rarefaction. J Clin Invest (2006) 116:1547-60. doi:10.1172/JCI25397

16. Bernardo BC, Weeks KL, Pretorius L, McMullen JR. Molecular distinction between physiological and pathological cardiac hypertrophy: experimental findings and therapeutic strategies. Pharmacol Ther (2010) 128:191-227. doi:10. 1016/j.pharmthera.2010.04.005

17. Dillmann W. Cardiac hypertrophy and thyroid hormone signaling. Heart Fail Rev (2010) 15:125-32. doi:10.1007/s10741-008-9125-7

18. Bassett JHD, Harvey CB, Williams GR. Mechanisms of thyroid hormone receptor-specific nuclear and extra nuclear actions. Mol Cell Endocrinol (2003) 213:1-11. doi:10.1016/j.mce.2003.10.033

19. Kenessey A, Ojamaa K. Thyroid hormone stimulates protein synthesis in the cardiomyocyte by activating the Akt-mTOR and p70S6K pathways. J Biol Chem (2006) 281:20666-72. doi:10.1074/jbc.M512671200

20. Cao X, Kambe F, Moeller LC, Refetoff S, Seo H. Thyroid hormone induces rapid activation of Akt/protein kinase B-mammalian target of rapamycinp70S6K cascade through phosphatidylinositol 3-kinase in human fibroblasts. Mol Endocrinol (2005) 19:102-12. doi:10.1210/me.2004-0093

21. Martin NP, Fernandez de Velasco EM, Mizuno F, Scappini EL, Gloss B, Erxleben $\mathrm{C}$, et al. A rapid cytoplasmic mechanism for PI3 kinase regulation by the nuclear thyroid hormone receptor, TR $\beta$, and genetic evidence for its role in the maturation of mouse hippocampal synapses in vivo. Endocrinology (2014) 155:3713-24. doi:10.1210/en.2013-2058

22. Thum T, Catalucci D, Bauersachs J. MicroRNAs: novel regulators in cardiac development and disease. Cardiovasc Res (2008) 79:562-70. doi:10.1093/cvr/ cvn 137

23. Van Rooij E, Sutherland LB, Liu N, Williams AH, McAnally J, Gerard RD, et al. A signature pattern of stress-responsive microRNAs that can evoke cardiac hypertrophy and heart failure. Proc Natl Acad Sci U S A (2006) 103:18255-60. doi:10.1073/pnas.0608791103

24. Da Costa Martins P, Salic K, Gladka MM, Armand A-S, Leptidis S, El Azzouzi $\mathrm{H}$, et al. MicroRNA-199b targets the nuclear kinase Dyrkla in an autoamplification loop promoting calcineurin/NFAT signalling. Nat Cell Biol (2010) 12:1220-7. doi: $10.1038 /$ ncb2126

25. Divakaran V, Mann DL. The emerging role of microRNAs in cardiac remodeling and heart failure. Circ Res (2008) 103:1072-83. doi:10.1161/CIRCRESAHA.108. 183087

26. van Rooij E, Sutherland LB, Qi X, Richardson J, Hill J, Olson EN. Control of stress-dependent cardiac growth and gene expression by a microRNA. Science (2007) 316:575-9. doi:10.1126/science.1139089

27. Callis TE, Pandya K, Seok HY, Tang R-H, Tatsuguchi M, Huang Z-P, et al. MicroRNA-208a is a regulator of cardiac hypertrophy and conduction in mice. J Clin Invest (2009) 119:2772-86. doi:10.1172/JCI36154

28. Montgomery RL, Hullinger TG, Semus HM, Dickinson B, Seto G, Lynch JM, et al. Therapeutic inhibition of miR-208a improves cardiac function and survival during heart failure. Circulation (2011) 124(14):1537-47. doi:10.1161/ CIRCULATIONAHA.111.030932

29. Diniz GP, Takano AP, Barreto-Chaves MLM. MiRNA-208a and miRNA-208b are triggered in thyroid hormone-induced cardiac hypertrophy - role of type 1 angiotensin II receptor (AT1R) on miRNA-208a/ $\alpha$-MHC modulation. Mol Cell Endocrinol (2013) 374:117-24. doi:10.1016/j.mce.2013.04.010

30. Dong H, Paquette M, Williams A, Zoeller RT, Wade M, Yauk C. Thyroid hormone may regulate mRNA abundance in liver by acting on microRNAs. PLoS One (2010) 5:e12136. doi:10.1371/journal.pone.0012136

31. Visser WE, Heemstra K, Swagemakers SM, Ozgür Z, Corssmit EP, Burggraaf J, et al. Physiological thyroid hormone levels regulate numerous skeletal muscle transcripts. J Clin Endocrinol Metab (2009) 94:3487-96. doi:10.1210/jc.20090782
32. Bagnall RD, Tsoutsman T, Shephard RE, Ritchie W, Semsarian C. Global MicroRNA profiling of the mouse ventricles during development of severe hypertrophic cardiomyopathy and heart failure. PLoS One (2012) 7:e44744. doi:10.1371/journal.pone.0044744

33. Shan Z-X, Lin Q-X, Fu Y-H, Deng C-Y, Zhou Z-L, Zhu J-N, et al. Upregulated expression of miR-1/miR-206 in a rat model of myocardial infarction. Biochem Biophys Res Commun (2009) 381:597-601. doi:10.1016/j.bbrc. 2009.02.097

34. Sluijter JPG, van Mil A, van Vliet P, Metz CHG, Liu J, Doevendans P, et al. MicroRNA-1 and -499 regulate differentiation and proliferation in humanderived cardiomyocyte progenitor cells. Arterioscler Thromb Vasc Biol (2010) 30:859-68. doi:10.1161/ATVBAHA.109.197434

35. Vo NK, Dalton RP, Liu N, Olson EN, Goodman RH. Affinity purification of microRNA-133a with the cardiac transcription factor, Hand2. Proc Natl Acad Sci U S A (2010) 107:19231-6. doi:10.1073/pnas.1013162107

36. Chomczynski P, Sacchi N. Single-step method of RNA isolation by acid guanidinium thiocyanate-phenol-chloroform extraction. Anal Biochem (1987) 159:156-9. doi:10.1006/abio.1987.9999

37. Mraz M, Malinova K, Mayer J, Pospisilova S. MicroRNA isolation and stability in stored RNA samples. Biochem Biophys Res Commun (2009) 390:1-4. doi:10.1016/j.bbrc.2009.09.061

38. Pol CJ, Muller A, Zuidwijk MJ, van Deel ED, Kaptein E, Saba A, et al. Left-ventricular remodeling after myocardial infarction is associated with a cardiomyocyte-specific hypothyroid condition. Endocrinology (2011) 152:669-79. doi:10.1210/en.2010-0431

39. Chen Y, Gelfond JL, McManus LM, Shireman PK. Reproducibility of quantitative RT-PCR array in miRNA expression profiling and comparison with microarray analysis. BMC Genomics (2009) 10:407. doi:10.1186/1471-2164-10-407

40. Bianco AC, Anderson G, Forrest D, Galton VA, Gereben B, Kim BW, et al. American thyroid association guide to investigating thyroid hormone economy and action in rodent and cell models. Thyroid (2014) 24:88-168. doi:10.1089/thy. 2013.0109

41. Braz JC, Bueno OF, Liang Q, Wilkins BJ, Dai Y-S, Parsons S, et al. Targeted inhibition of p38 MAPK promotes hypertrophic cardiomyopathy through upregulation of calcineurin-NFAT signaling. J Clin Invest (2003) 111:1475-86. doi:10.1172/JCI17295

42. Takimoto E, Yao A, Toko H, Takano H, Shimoyama M, Sonoda M, et al. Sodium calcium exchanger plays a key role in alteration of cardiac function in response to pressure overload. FASEB J (2002) 16:373-8. doi:10.1096/fj.01$0735 \mathrm{com}$

43. Ichihara S, Senbonmatsu T, Price E, Ichiki T, Gaffney FA, Inagami T. Angiotensin II type 2 receptor is essential for left ventricular hypertrophy and cardiac fibrosis in chronic angiotensin II-induced hypertension. Circulation (2001) 104:346-51. doi:10.1161/01.CIR.104.3.346

44. Chang L, Zhang J, Tseng Y-H, Xie C-Q, Ilany J, Brüning JC, et al. Rad GTPase deficiency leads to cardiac hypertrophy. Circulation (2007) 116:2976-83. doi:10.1161/CIRCULATIONAHA.107.707257

45. Li C, Cai X, Sun H, Bai T, Zheng X, Zhou XW, et al. The $\delta$ A isoform of calmodulin kinase II mediates pathological cardiac hypertrophy by interfering with the HDAC4-MEF2 signaling pathway. Biochem Biophys Res Commun (2011) 409:125-30. doi:10.1016/j.bbrc.2011.04.128

46. Panek AN, Posch MG, Alenina N, Ghadge SK, Erdmann B, Popova E, et al. Connective tissue growth factor overexpression in cardiomyocytes promotes cardiac hypertrophy and protection against pressure overload. PLoS One (2009) 4:e6743. doi:10.1371/journal.pone.0006743

47. Szabó Z, Magga J, Alakoski T, Ulvila J, Piuhola J, Vainio L, et al. Connective tissue growth factor inhibition attenuates left ventricular remodeling and dysfunction in pressure overload-induced heart failure. Hypertension (2014) 63:1235-40. doi:10.1161/HYPERTENSIONAHA.114.03279

48. Wei JQ, Shehadeh L, Mitrani JM, Pessanha M, Slepak TI, Webster K, et al. Quantitative control of adaptive cardiac hypertrophy by acetyltransferase p300. Circulation (2008) 118:934-46. doi:10.1161/CIRCULATIONAHA.107.760488

49. Yanazume T, Hasegawa K, Morimoto T, Kawamura T, Wada H, Matsumori A, et al. Cardiac p300 is involved in myocyte growth with decompensated heart failure. Mol Cell Biol (2003) 23:3593-606. doi:10.1128/MCB.23.10.35933606.2003

50. Zhang S, Weinheimer C, Courtois M, Kovacs A, Zhang CE, Cheng AM, et al. The role of the Grb2-p38 MAPK signaling pathway in cardiac hypertrophy and fibrosis. J Clin Invest (2003) 111:833-41. doi:10.1172/JCI16290 
51. Krishnan J, Suter M, Windak R, Krebs T, Felley A, Montessuit C, et al. Activation of a HIFlalpha-PPARgamma axis underlies the integration of glycolytic and lipid anabolic pathways in pathologic cardiac hypertrophy. Cell Metab (2009) 9:512-24. doi:10.1016/j.cmet.2009.05.005

52. Lairez O, Cognet T, Schaak S, Calise D, Guilbeau-Frugier C, Parini A, et al. Role of serotonin 5-HT2A receptors in the development of cardiac hypertrophy in response to aortic constriction in mice. J Neural Transm (2013) 120:927-35. doi:10.1007/s00702-013-1011-3

53. Jiang D-S, Liu Y, Zhou H, Zhang Y, Zhang X-D, Zhang X-F, et al. Interferon regulatory factor 7 functions as a novel negative regulator of pathological cardiac hypertrophy. Hypertension (2014) 63:713-22. doi:10.1161/ HYPERTENSIONAHA.113.02653

54. Purcell NH, Tang G, Yu C, Mercurio F, DiDonato JA, Lin A. Activation of NF-kappa B is required for hypertrophic growth of primary rat neonatal ventricular cardiomyocytes. Proc Natl Acad Sci U S A (2001) 98:6668-73. doi:10.1073/pnas. 111155798

55. Clemente CFMZ, Tornatore TF, Theizen TH, Deckmann AC, Pereira TC, LopesCendes I, et al. Targeting focal adhesion kinase with small interfering RNA prevents and reverses load-induced cardiac hypertrophy in mice. Circ Res (2007) 101:1339-48. doi:10.1161/CIRCRESAHA.107.160978

56. Métrich M, Lucas A, Gastineau M, Samuel J-L, Heymes C, Morel E, et al. Epac mediates beta-adrenergic receptor-induced cardiomyocyte hypertrophy. Circ Res (2008) 102:959-65. doi:10.1161/CIRCRESAHA.107.164947

57. Wu X, Cao Y, Nie J, Liu H, Lu S, Hu X, et al. Genetic and pharmacological inhibition of Rheb1-mTORC1 signaling exerts cardioprotection against adverse cardiac remodeling in mice. Am J Pathol (2013) 182:2005-14. doi:10.1016/j. ajpath.2013.02.012

58. Manso AM, Li R, Monkley SJ, Cruz NM, Ong S, Lao DH, et al. Talin1 has unique expression versus talin 2 in the heart and modifies the hypertrophic response to pressure overload. J Biol Chem (2013) 288:4252-64. doi:10.1074/jbc.M112. 427484

59. DeBosch B, Treskov I, Lupu TS, Weinheimer C, Kovacs A, Courtois M, et al. Akt1 is required for physiological cardiac growth. Circulation (2006) 113:2097-104. doi:10.1161/CIRCULATIONAHA.105.595231

60. Matsui T, Li L, Wu JC, Cook SA, Nagoshi T, Picard MH, et al. Phenotypic spectrum caused by transgenic overexpression of activated Akt in the heart. J Biol Chem (2002) 277:22896-901. doi:10.1074/jbc.M200347200

61. Chen L, Hahn H, Wu G, Chen CH, Liron T, Schechtman D, et al. Opposing cardioprotective actions and parallel hypertrophic effects of delta $\mathrm{PKC}$ and epsilon PKC. Proc Natl Acad Sci U S A (2001) 98:11114-9. doi:10.1073/pnas.191369098

62. Baurand A, Zelarayan L, Betney R, Gehrke C, Dunger S, Noack C, et al. Betacatenin downregulation is required for adaptive cardiac remodeling. Circ Res (2007) 100:1353-62. doi:10.1161/01.RES.0000266605.63681.5a

63. Yang K-C, Jay PY, McMullen JR, Nerbonne JM. Enhanced cardiac PI3K $\alpha$ signalling mitigates arrhythmogenic electrical remodelling in pathological hypertrophy and heart failure. Cardiovasc Res (2012) 93:252-62. doi:10.1093/cvr/ cvr283

64. McMullen JR, Shioi T, Zhang L, Tarnavski O, Sherwood MC, Kang PM, et al. Phosphoinositide 3-kinase(p110alpha) plays a critical role for the induction of physiological, but not pathological, cardiac hypertrophy. Proc Natl Acad Sci U S A (2003) 100:12355-60. doi:10.1073/pnas.1934654100

65. Haq S, Kilter H, Michael A, Tao J, O'Leary E, Sun XM, et al. Deletion of cytosolic phospholipase A2 promotes striated muscle growth. Nat Med (2003) 9:944-51. doi: $10.1038 / \mathrm{nm} 891$

66. Ojamaa K. Signaling mechanisms in thyroid hormone-induced cardiac hypertrophy. Vascul Pharmacol (2010) 52:113-9. doi:10.1016/j.vph.2009.11.008

67. Kinugawa K, Yonekura K, Ribeiro RC, Eto Y, Aoyagi T, Baxter JD, et al. Regulation of thyroid hormone receptor isoforms in physiological and pathological cardiac hypertrophy. Circ Res (2001) 89:591-8. doi:10.1161/hh1901.096706

68. Lee HW, Klein LE, Raser J, Eghbali-Webb M. An activator protein-1 (AP1) response element on pro alpha1(l) collagen gene is necessary for thyroid hormone-induced inhibition of promoter activity in cardiac fibroblasts. $J \mathrm{Mol}$ Cell Cardiol (1998) 30:2495-506. doi:10.1006/jmcc.1998.0811

69. Ghose Roy S, Mishra S, Ghosh G, Bandyopadhyay A. Thyroid hormone induces myocardial matrix degradation by activating matrix metalloproteinase1. Matrix Biol (2007) 26:269-79. doi:10.1016/j.matbio.2006.12.005

70. Grueter C, van Rooij E, Johnson B, DeLeon S. A cardiac microRNA governs systemic energy homeostasis by regulation of MED13. Cell (2012) 149:671-83. doi:10.1016/j.cell.2012.03.029
71. Ito M, Roeder RG. The TRAP/SMCC/mediator complex and thyroid hormone receptor function. Trends Endocrinol Metab (2001) 12:127-34. doi:10.1016/ S1043-2760(00)00355-6

72. Malik S, Roeder RG. Dynamic regulation of pol II transcription by the mammalian mediator complex. Trends Biochem Sci (2005) 30:256-63. doi:10.1016/j. tibs.2005.03.009

73. Martinelli NC, Cohen CR, Santos KG, Castro M, Biolo A, Frick L, et al. An analysis of the global expression of microRNAs in an experimental model of physiological left ventricular hypertrophy. PLoS One (2014) 9:e93271. doi:10.1371/journal.pone.0093271

74. Kress E, Samarut J, Plateroti M. Thyroid hormones and the control of cell proliferation or cell differentiation: paradox or duality? Mol Cell Endocrinol (2009) 313:36-49. doi:10.1016/j.mce.2009.08.028

75. López M, Alvarez CV, Nogueiras R, Diéguez C. Energy balance regulation by thyroid hormones at central level. Trends Mol Med (2013) 19:418-27. doi:10.1016/j.molmed.2013.04.004

76. Anderson ME. CaMKII and a failing strategy for growth in heart. J Clin Invest (2009) 119:1082-5. doi:10.1172/JCI39262

77. Sano M, Minamino T, Toko H, Miyauchi H, Orimo M, Qin Y, et al. p53-induced inhibition of Hif-1 causes cardiac dysfunction during pressure overload. Nature (2007) 446:444-8. doi:10.1038/nature05602

78. Zhang T, Johnson EN, Gu Y, Morissette MR, Sah VP, Gigena MS, et al. The cardiac-specific nuclear delta(B) isoform of $\mathrm{Ca} 2+/$ calmodulin-dependent protein kinase II induces hypertrophy and dilated cardiomyopathy associated with increased protein phosphatase 2A activity. J Biol Chem (2002) 277:1261-7. doi:10.1074/jbc.M108525200

79. Zhang R, Khoo MSC, Wu Y, Yang Y, Grueter CE, Ni G, et al. Calmodulin kinase II inhibition protects against structural heart disease. Nat Med (2005) 11:409-17. doi: $10.1038 / \mathrm{nm} 1215$

80. Zhang W, Qi F, Chen D-Q, Xiao W-Y, Wang J, Zhu W-Z. Ca2+/calmodulindependent protein kinase IIdelta orchestrates G-protein-coupled receptor and electric field stimulation-induced cardiomyocyte hypertrophy. Clin Exp Pharmacol Physiol (2010) 37:795-802. doi:10.1111/j.1440-1681.2010. 05382.x

81. Hayata N, Fujio Y, Yamamoto Y, Iwakura T, Obana M, Takai M, et al. Connective tissue growth factor induces cardiac hypertrophy through Akt signaling. Biochem Biophys Res Commun (2008) 370:274-8. doi:10.1016/j.bbrc.2008.03.100

82. Schaub MC, Hefti M, Harder B, Eppenberger HM. Various hypertrophic stimuli induce distinct phenotypes in cardiomyocytes. J Mol Med (Berl) (1997) 75:901-20. doi:10.1007/s001090050182

83. Shiojima I, Sato K, Izumiya Y, Schiekofer S, Ito M, Liao R, et al. Disruption of coordinated cardiac hypertrophy and angiogenesis contributes to the transition to heart failure. J Clin Invest (2005) 115:2108-18. doi:10.1172/ JCI24682

84. Shiojima I, Walsh K. Regulation of cardiac growth and coronary angiogenesis by the Akt/PKB signaling pathway. Genes Dev (2006) 20:3347-65. doi:10.1101/gad.1492806

85. Chaanine AH, Hajjar RJ. AKT signalling in the failing heart. Eur J Heart Fail (2011) 13:825-9. doi:10.1093/eurjhf/hfr080

86. Warner MH, Beckett GJ. Mechanisms behind the non-thyroidal illness syndrome: an update. J Endocrinol (2010) 205:1-13. doi:10.1677/JOE-09-0412

87. Pantos C, Dritsas A, Mourouzis I, Dimopoulos A, Karatasakis G, Athanassopoulos G, et al. Thyroid hormone is a critical determinant of myocardial performance in patients with heart failure: potential therapeutic implications. Eur J Endocrinol (2007) 157:515-20. doi:10.1530/EJE-07-0318

88. Pingitore A, Landi P, Taddei MC, Ripoli A, L'Abbate A, Iervasi G. Triiodothyronine levels for risk stratification of patients with chronic heart failure. Am J Med (2005) 118:132-6. doi:10.1016/j.amjmed.2004.07.052

89. Olivares EL, Marassi MP, Fortunato RS, da Silva ACM, Costa-e-Sousa RH, Araújo IG, et al. Thyroid function disturbance and type 3 iodothyronine deiodinase induction after myocardial infarction in rats a time course study. Endocrinology (2007) 148:4786-92. doi:10.1210/en.2007-0043

90. Wassen FWJS, Schiel AE, Kuiper GGJM, Kaptein E, Bakker O, Visser $\mathrm{TJ}$, et al. Induction of thyroid hormone-degrading deiodinase in cardiac hypertrophy and failure. Endocrinology (2002) 143:2812-5. doi:10.1210/endo.143.7. 8985

91. Van Rooij E, Marshall WS, Olson EN. Toward microRNA-based therapeutics for heart disease: the sense in antisense. Circ Res (2008) 103:919-28. doi:10.1161/CIRCRESAHA.108.183426 
92. Latronico MVG, Condorelli G. Therapeutic use of microRNAs in myocardial diseases. Curr Heart Fail Rep (2011) 8:193-7. doi:10.1007/s11897-0110068-2

Conflict of Interest Statement: The authors declare that the research was conducted in the absence of any commercial or financial relationships that could be construed as a potential conflict of interest.

Received: 31 July 2014; paper pending published: 04 September 2014; accepted: 30 September 2014; published online: 20 October 2014.
Citation: Janssen R, Zuidwijk MJ, Kuster DWD, Muller A and Simonides WS (2014) Thyroid hormone-regulated cardiac microRNAs are predicted to suppress pathological hypertrophic signaling. Front. Endocrinol. 5:171. doi: 10.3389/fendo.2014.00171 This article was submitted to Thyroid Endocrinology, a section of the journal Frontiers in Endocrinology.

Copyright (c) 2014 Janssen, Zuidwijk, Kuster, Muller and Simonides. This is an openaccess article distributed under the terms of the Creative Commons Attribution License (CC BY). The use, distribution or reproduction in other forums is permitted, provided the original author(s) or licensor are credited and that the original publication in this journal is cited, in accordance with accepted academic practice. No use, distribution or reproduction is permitted which does not comply with these terms. 